\title{
Exploring Quality of Life Reported by Norwegian Older Adults Using Classification Tree Approach on Group Profiles
}

\author{
Lidia Santora $^{1,2}$ (D) Don Byrne ${ }^{3} \cdot$ Christian Klöckner $^{4}$
}

Accepted: 24 July 2021 / Published online: 12 August 2021

(c) The Author(s) 2021

\begin{abstract}
This study aims to explore the variation between- and within subgroups of older adults with regard to low, medium, and high levels of self-reported quality of life (QoL) measured by the WHOQOL-BREF scale. The contribution of interacting personal and contextual life conditions to QoL was examined in a sample of 1,910 (sample frame 6,000) Norwegian men and women aged 62 to 99 years. The data collected by a postal questionnaire were analyzed using the Chi-square Automatic Interaction Detection (CHAID) classification method in order to detect unique profiles of groups who shared common characteristics. The CHAID model revealed 15 relatively homogenous groups, but distinct from one another, whose profiles were defined by unique constellations of several interacting variables significantly related to a given QoL level. Mental functioning was predominantly linked to perception of life meaning along with health status, and/or in some cases living arrangement, loneliness, neighborhood quality, and satisfaction with income, and placed an individual at different likelihood levels of reporting low, medium, or high QoL. Sociodemographics had no statistically significant impact on QoL for any subgroup. Through this individual-oriented approach, a periodically ongoing assessment of subjective quality of life (QoL) may be sufficiently powerful to allow detecting and addressing personal concerns and specific needs that detract from quality of life in advancing age.
\end{abstract}

Keywords Quality of life · Older adults · WHOQOL-BREF · CHAID

Lidia Santora

lidia.santora@ntnu.no

1 Department of Public Health and Nursing, Norwegian University of Science and Technology, Høgskoleringen 1, 7491 Trondheim, Norway

2 Research School of Psychology, Australian National University, , Canberra, ACT 0200, Australia

3 College of Health and Medicine, Australian National University, , Canberra, ACT 0200, Australia

4 Department of Psychology, Norwegian University of Science and Technology, Edvard Bulls veg 1, Dragvoll, 7491 Trondheim, Norway 


\section{Exploring Quality of Life Reported by Norwegian Older Adults Using Classification Tree Approach on Group Profiles}

In Norway, high quality of life (QoL) at the population level has remained relatively unchanged since 2005 (Nes, 2019). This stability connects with the most recent national report, which concludes that the majority of older adults (persons 65 years and older) in the country enjoy a good QoL (Hansen \& Daatland, 2016; Nes et al., 2020). One of the most common explanations links it to the generous Norwegian welfare system which closely adheres to the principles of social justice (Hansen \& Daatland, 2016; Kalfoss et al., 2008) coupled with a high sensitivity to difficult circumstances in which some people may live (Sund et al., 2007). Although social policies and egalitarian values in Norway may facilitate its older population's welfare through the provision of resources and equal opportunities needed to enhance and sustain good life quality (e.g., a universal pension policy and equity in services provision), its distribution remains nonetheless uneven, and this constitutes an issue of largely unmet concern for Norway's social authorities. To date, the minority or the most vulnerable older persons identified as demanding attention are those troubled by depression, loneliness, and recipients of the minimum age pension living alone who, in Norway, are nearly all women (Hansen \& Daatland, 2016). International studies of QoL in both western and non-western societies with similar welfare states show similar concerns (Hermalin et al., 2002; Kirchengast \& Haslinger, 2008; Lubetkin et al., 2005; Zaninotto et al., 2009).

Research over the last 20 or so years regularly show that satisfactory QoL tends to be strongly linked to good health and functional ability, the experience of strong family ties, a secure financial situation, leisure, and good living conditions (e.g., comfort, available to people goods and necessities) (Gabriel \& Bowling, 2004; Hansen \& Daatland, 2016; Kalfoss \& Halvorsrud, 2009; Nes et al., 2020; Paskulin \& Molzahn, 2007; Puts et al., 2007; Statistics Norway, 2020; Wilhemson et al., 2005), and particularly for those in the older age group, satisfaction with their neighborhood (Gabriel \& Bowling, 2004; Nes et al., 2020; Statistics Norway, 2020). On the down side, painful medical conditions, chronic disease, functional disabilities, loneliness, lack of help for those alone and in poor health, financial strain, poor family bonds, and lack of friends, all significantly decrease a person's QoL (Bowling et al., 2003; Hellström et al., 2004; Helvik et al., 2011; Puts et al., 2007; Zaninotto et al., 2009). Any of these factors alone or in some combination are also powerful correlates of self-neglect (Mosqueda \& Dong, 2011), and of depression, which in turn severely reduces QoL and the sense of subjective well-being (Blazer, 2003; Cummins et al., 2007; Hellström et al., 2004; Scocco \& Nassuato, 2017; Sivertsen et al., 2015). In addition, Pinquart (2002) has observed that for older adults in particular, physical health status (e.g., mobility, vision) is a key determinant of perceptions of meaning in life. The meaning of life within the context of well-being has salience when personally significant goals and potentials are achieved or are achievable (Ryff \& Keyes, 1995). Seeing life as meaningful has been positively associated with QoL (McDonald et al., 2012; Paskulin \& Molzahn, 2007), longevity and positive health outcomes 
(Boyle et al., 2009), reporting fewer symptoms when ill (McKnight \& Kashdan, 2009), feelings of hope (Mascaro \& Rosen, 2005), good social relations, and competence to perform daily activities (Pinquart, 2002). However, the decline or loss of meaning in life is associated with lack of or being unable to find purpose, indifference, feelings of emptiness, apathy, detachment from self and others, hopelessness (resignation), and perceived lack of control over life situations (Mascaro \& Rosen, 2005; McDonald et al., 2012; Pinquart, 2002; Schnell, 2009; Zika \& Chamberlain, 1992). Under these circumstances, a person is likely to experience a condition called an 'existential vacuum' (Reker et al., 1987). A national population study reports that from the 75 years and above experiencing "little meaning in everyday life" increases and this parallels with reporting decreasing satisfaction with life (Nes et al., 2020).

In general, when assessed within older populations of different western countries, QoL exhibits a weak age gradient. The majority of investigations have demonstrated that QoL tends only to slightly decrease with advanced age, especially, but not necessarily after the age of 75 to 80 years (Hansen \& Daatland, 2016; Hawthorne et al., 2006; Motel-Klingebiel et al., 2004; Netuveli et al., 2006; Von dem Knesebeck et al., 2007). The reduced QoL with advancing age seems to be expected even by older persons themselves (Lacy et al., 2006). For example, in Norwegian population study (Statistics Norway, 2020), 50 percent of respondents aged 80 years and over believed that their current QoL will be reduced in about five years. On the contrary, both longitudinal and cross-sectional studies consistently report that QoL may in fact increase with advanced age, especially for those not troubled by illness or among those who have strong family relations (Netuveli et al., 2006; Zaninotto et al., 2009). Thus, despite the widespread assumptions about late life as universally filled with pain and sadness, to the contrary most older people maintain a positive sense of well-being. This phenomenon has been referred to as the paradox of well-being (Mroczek \& Kolarz, 1998) and has been connected to the U-shaped hypothesis on curvilinear relation between happiness and age; happiness declines towards the ages 35 to 50 and then rises again from age 40 to 80 (Hansen \& Slagsvold, 2012). The U-shaped association between life satisfaction and age is observed in relatively wealthy countries including Norway indicating that influence of national context may have larger effect on particular groups within a society (Hansen \& Slagsvold, 2012; Morgan et al., 2015; Swift et al., 2014). Notably, in the study of life satisfaction in the life-span perspective in 30 OECD member states, Fischer (2009) observed that for a third of the countries (including those in Scandinavia), there was a hyperbolic age effect on happiness; satisfaction was high in childhood, decreased throughout middle age, then increased again with a peak early in the eighth decade of life, after which satisfaction with life declined again. Bäckman and MacDonald (2006) asserted that among other things, preserved health and intact cognitive functioning may be very important protectors against age-related reductions of QoL in later life stages. However, in the final years of life (on average, the last three to five years), QoL is less likely to be reported as good, although the experience of a terminal decline through steep and accelerated decrements in levels of well-being varies widely between individuals (Brandmaier et al., 2017; Gerstorf et al., 2010; Vogel et al., 2013). 
Some studies have detected geographical variations in reported living conditions in relation to overall QoL (Barstad, 1995; Hansen \& Daatland, 2016; Mastekaasa \& Moum, 1984; Tavares et al., 2014), well-being (Inder et al., 2012), and health-related QoL in older adults (Weeks et al., 2004). One clear example of this addresses the urban-(semi)rural region of residence, which has been suggested by geographic gerontologists (Skinner et al., 2014) and other researchers (e.g., Kalfoss et al., 2017), as an important contextual factor worth scientific inquiry into aging related issues. For example, according to Statistics Norway (2016) older people living alone in urban areas find it hard to get help when needed from neighbors, although this is not consistent across regions. On the other hand, it has been reported that in comparison to older people in urban areas, aging of those living in rural communities seems to be easier due to longstanding and strong social ties, and feelings of belonging (Blekesaune \& Haugen, 2018; Carta et al., 2012; Kalfoss et al., 2017; Milbourne, 2012; Tavares et al., 2014). Conversely, it has been shown that in rural as opposed to urban settings, older people tend to report poorer physical and mental health (Kalfoss et al., 2017). These findings, however are not always consistent across studies (Inder et al., 2012; Kalfoss et al., 2017). Moreover, compared to their urban peers older rural residents tend to experience more social isolation, report lower social functioning (Bascu et al., 2014; Milbourne, 2012), and unnoticed loneliness which has gone undetected by medical or social services (Burholt \& Dobbs, 2012), and when depressed have a higher preference for use of antidepressants relative to counseling (Fortney et al., 2010; Inder et al., 2012). There is also evidence from Australian studies that suicide after the age 65, especially in older men living in rural communities, is increasing (Inder et al., 2012) and it is generally higher than in urban areas (Crnek-Georgeson et al., 2017).

The rationale for the present study is that the ongoing assessment of subjective QoL is an important means to detecting and addressing the concerns and needs that are relevant for a person entering the older age groups. According to the World Health Organization (WHO) (1998), QoL is defined from the transcultural perspective as:

Individuals' perceptions of their position in life in the context of the culture and value systems in which they live and in relation to their goals, expectations, standards and concerns. It is a broad ranging concept affected in a complex way by the individual's physical health, psychological state, level of independence, social relationships, personal beliefs, and their relationship to salient features of their environment. (p. 1405)

The conceptualization of QoL is guided by the principle that the components of QoL are the same for all people. A wide range of indicators, encompassing both personal and environmental aspects of life are therefore indicated by the WHO definition, and are consequently included in the World Health Organization Quality of Life-BREF (WHOQOL-BREF) scale (WHO, 1998) which has been applied in the research to be reported below.

\section{Research Objective}

The overarching aim of this study was to explore the various and diverse characteristics of sub-groups of the Norwegian older population with regard to different levels of self-reported QoL as defined by physical health, mental health, social functioning 
and environmental aspects of life, with each of these elements to be assessed by the WHOQOL-BREF scale (WHO, 1998), and in relation to previously identified psychosocial correlates of QoL, including loneliness, inadequate living arrangements, neighborhood characteristics, and geodemographic characteristics.

Exploring personal and environmental variables related to the QoL is important for two main reasons. First, quality of life studies using samples drown from population of older adults have already implicated several personal and contextual factors (e.g., physical health, psychological functioning, and social factors) relevant to the perception of subjective QoL. However, to date none of the Norwegian (and international) studies have investigated the possibility that broad range of determinants of QoL in specific constellations may have on detecting the nature and sources of between- and within-group differences on QoL levels. By employing an underutilized in social and health sciences classification (or decision) tree method, this study is thought to add new knowledge by illustration how this methodological approach can make contribution to understanding how and what life circumstances may affect life quality in community residing older adults. Second, it has been proposed that generic QoL assessments could serve as a valuable benchmark for detecting and addressing the needs of each person (Pennacchini et al., 2011; Raphael, 2010; Skevington \& O'Connell, 2004). In Norway, there are no structured and systematic QoL assessments incorporated into health and social care service practices. We hope that our study will provide a useful information and possibly serve as an impetus for future research investigations on the utility of the generic QoL assessment in applied settings, foremost for ethical reasons and a recognition of the fact that older adults in particular welcome questions concerning their life situation (Llewellyn \& Skevington, 2016).

In order to describe profiles of sub-groups based on these diverse but centrally informative factors, we applied the Decision Tree procedure: the Chi-Square Automatic Interaction Detection (CHAID) classification method (IBM, 2012), which enables us to identify the profiles of older adults as indicated by the constellations of interacting factors significantly related to reported QoL level. In this study, we address the question:

What sets of factors characterize groups ranging between the lowest and highest scores on the WHOQOL-BREF scale of quality of life?

\section{Method}

\section{Participants and Procedure}

This paper reports a cross-sectional study based on data obtained from a postal survey sent to a randomly drawn sample frame of 6,000 men and women aged 62 and over living in one county (Sør-Trøndelag [S-T]) located in the mid part of Norway. Sampling took place just once and did not involve replacement for non-responses. Based on the 2015 Census year (Statistics Norway, 2015), the sample frame represents about $10 \%$ of the eligible target population in S-T of 57,972 inhabitants aged 62 and older. Due to a flexible retirement scheme, Norwegians are entitled to 
commence retirement from the age of 62 (the statutory and mandatory age is 67 and 70 years for women and men respectively). Although it can only serve as an arbitrary demarcation for older adulthood, the minimum age of 62 years was set to meet eligibility criteria for participation in the study. There were no exclusion criteria, although participation would require sufficient knowledge of the Norwegian language to be able to read and to fill out the paper-and-pencil questionnaire.

The survey questionnaire was 12-pages long and consisted of a total of 150 items. Items selected in this study assessed quality of life measured by the World Health Organization Quality of Life-BREF (WHOQOL-BREF) scale (WHO, 1998), together with questions on a number of personal and environmental factors such as sociodemographics, loneliness, living arrangements, neighborhood qualities, and rural/semi-rural/urban regionality.

The 6,000 questionnaires along with an invitation letter stating the thematic content and the purpose of the study were distributed by post to potential respondents. Due to the sensitive nature of some questions included in the survey, a clear statement was provided to assure participants of the strict anonymity of responses, and potential respondents were free to decline to answer particular question(s) should they choose to do so. Given the conditions of complete anonymity, the (un)returned questionnaires could not be linked to any identifying information on potential respondents. Returned and completed questionnaires were taken to demonstrate consent to participate in the study. Due to privacy protection, no information on completion of the questionnaire could be collected, thus no reminder letter could be sent. Data were collected between May and September 2015. Out of the sample frame of $6,000,1,910$ persons ( $32 \%$ participation rate) responded to the survey with usable information (defined as $51 \%$ or more of valid answers to survey items). The appropriate statistical methods of missing data substitution will be described later in the paper.

\section{Measures}

\section{Measurement Considerations}

The CHAID algorithm method (described in more detail below in subsection CHAID Analysis) operates on nominal and/or ordinal scaled categorical variables as well as continuous variables with converted scores into two or more categories (Kass, 1980).

\section{Quality of Life}

The WHOQOL-BREF (WHO, 1998) is a generic QoL assessment tool, which comprises a total of 26 items. The 24 items are arranged into four dimensions (domains) of Physical (PHYS) (7 items); Psychological (PSY) (6 items); Social (SOC) (3 items); and Environmental (8 items). Two further global items measure Overall Quality of Life and General Health. Each item is rated on a five-point Likert scale 
(e.g., $1=$ very dissatisfied, $2=$ dissatisfied to $5=$ very satisfied) with reference to the last two weeks. Higher score values indicate better QOL. For each domain total mean score value was calculated. According to the WHO supplied protocol (WHO, 1998), the QoL assessment is to be discarded when there is more than $20 \%$ missing data, and this was followed in the present study.

The psychometric properties of the WHOQOL-BREF among older adults (60 years and over) have been investigated in Taiwan (Hwang et al., 2003), Australia (Hawthorne et al., 2006), Switzerland (Von Steinbüchel et al., 2006), Brazil (Chachamovich et al., 2007), Norway and Canada (Kalfoss et al., 2008), Spain (Carrasco et al., 2011), and Singapore (Suárez et al., 2018). Overall, these studies have documented satisfactory reliability and validity (e.g., construct-, convergent-, and discriminant validity) of the scale. The internal consistency coefficients (Cronbach's $\alpha$ ) for the WHOQOLBREF across four domains ranged from 0.89 in the PHYS domain to 0.55 in the SOC domain. In the current study the Cronbach $\alpha$ 's for the domains were as follows: PHYS $\alpha=0.87$; PSY $\alpha=0.82$; SOC $\alpha=0.60$; and ENVIR $\alpha=0.83$. The domains and facets of the WHOQOL-BREF are listed in Appendix A.

In this study, the dependent variable (DV) is the global item Overall Quality of Life based on the question: How would you rate your quality of life? Five response options from very poor $=1$, poor $=2$, neither poor nor $\operatorname{good}=3$, good $=4$, and very good $=5$ were recoded into three categories labeled as follows: low $=1$ (merged categories: 1 and 2); medium $=2$ (data in category 3 left intact); and high=3 (merged categories: 4 and 5). The global General Health item is the independent variable (IV) with five categories coded according to the level of satisfaction with health from $1=$ very dissatisfied to $5=$ very satisfied which were transformed into three categories: $1=$ (very) dissatisfied (merged categories: very dissatisfied and fairly dissatisfied); $2=$ fair (data in original category neither satisfied nor dissatisfied left intact); $3=$ (very) satisfied (merged categories: satisfied and very satisfied). The recoding of categories for the two items from five to three requires a brief explanation. Regarding the DV, for interpretative purposes, in CHAID analysis it is not recommended to include the DV with more than two or three categories (IBM, 2012). This is because for each added category (e.g., above three) on the DV, the interpretative difficulties will increase due to disproportional increase in tree 'branches' (subgroups) and 'leaves' (nodes), hence rendering the interpretation of results very difficult. In addition, based on preliminary CHAID analysis, the CHAID model with the original five values on IV General Health would result in a very complex information predominantly for groups with medium QoL scores. Although the within medium QoL group variability would increase, the differences between subgroups with medium QoL scores would be very subtle, hence more difficult to interpret. Considering the explorative nature of this study, the Overall Quality of Life and General Health items with recoded values provide sufficient information to meet our research objective. The WHOQOL-BREF four domains serve as four IVs. The value ranges on PHYS, PSYCH, ENVIR domains are based on quintiles: $1^{\text {st }}=$ lowest, $2^{\text {nd }}=$ low, $3^{\text {rd }}=$ medium, $4^{\text {th }}=$ high, and $5^{\text {th }}=$ very high. The value ranges on SOC domain are based on quartiles due to granularity in the data allowing binning with a maximum of three cut-points with equal percentiles: $1^{\text {st }}=$ lowest, $2^{\text {nd }}=$ low-medium, $3^{\text {rd }}=$ medium - high, and $4^{\text {th }}=$ high . 


\section{Sociodemographic Variables: Age, Sex, Education, and Living Area}

The age of respondents was categorized into five groups following age classifications in previously published academic works and international age grouping recommendations (United Nations, 1982, 2003) of mainly 5-year intervals in sub-grouping of chronological age, and with following categories: 62-67, 68-74, 75-79, 80-84, 85 and older. Sex/gender was coded as $1=$ women and 2=men. Education was coded on a three-point scale as follows: primary or part of $i t=1$, any secondary $=2$, and tertiary $=3$. The geographic area of residence was classified by centrality (distance to a major urban centre), urbanization level (primary industries), and population density which permits fairly accurate identification of major regional differences as described in Blekesaune and Haugen (2018). The original seven categories of possible living areas in Norway (note: not marked by either postcode or name) were transformed into three separate variables coded (yes $=1$; no $=0$ ) as follows: rural (agricultural, sparsely populated, not suburban areas), semirural (areas without farming or small towns in the countryside), and urban (may include suburban, densely populated areas).

\section{Psychosocial Variables: Loneliness and Living Arrangement}

Loneliness was measured by a single question: How often during the last 12 months have you felt lonely? Five response options from $1=$ never to $5=$ very often were recoded into three categories: never $=1$ (data in original category left intact); sometimes $=2$ (merged categories: very seldom and sometimes); and often $=3$ (merged categories: often and very often). Type of living arrangement in terms of five separate variables included living: alone, with spouse/partner, with multigenerational family, with friends, and in an institution. An affirmative answer to any option was coded 1 .

\section{Neighborhood Characteristics}

The perception of neighborhood characteristics was assessed by the question: How do you feel about the community you live in? The three aspects of neighborhood (three variables) included in this study were: I can rely on help from neighbors when needed, I feel I belong to this place, and I find it difficult to get in contact with neighbors. The level of agreement with each statement from strongly disagree $=1$ to strongly agree $=5$ was recoded from five into three categories $1=$ (strongly) disagree; $2=$ neutral; $3=$ (strongly) agree, providing a separate 3-point code for each of the three aspects of neighborhood (e.g., code 1 implies poor characteristics of neighborhood). The rationale for merging five categories into three on each variable is similar to one described above in the subsection on Quality of Life. 


\section{Data Analysis}

\section{Descriptive Statistics}

Analysis of the sample characteristics by global OoL score were complemented by comparisons of low, medium, and high QoL score groups using chi-square tests for comparison of counts $(p<0.05)$.

\section{CHAID Analysis}

We performed CHAID analysis to explore the profiles of groups with low, medium and high QoL scores characterized by constellations of interacting categories of IVs.

The CHAID classification method is based on a recursive portioning algorithm that searches for an optimal decision in creating tree structures using a series of iterative chi-square tests between the DV and a number of IVs. It has the ability to identify significantly different, mutually exclusive and homogenous subgroups of the population who share similar characteristics in terms of a unique multivariable configuration most strongly linked to an outcome variable (i.e., QoL score). The CHAID method generates a tree-like structural output starting with the 'root' node comprising of the entire sample, which then, based on the most significant IVs (with the smallest $p$ value, the largest $\chi^{2}$ ), is further split into branches with ensuing 'parent' and 'child' nodes contingent on each other. The categories of the splitting variable chosen by CHAID which do not significantly differ from each other or are not independent on the outcome variable can be merged together and then treated as a single category (e.g., categories: > low or low and medium). The end of each branch is marked by terminal/end node which reveals the best classification predictions for the model and the last IV value that minimizes a measure of within-group heterogeneity (IBM, 2012). The number of end nodes indicates the number of most homogenous sub-groups/segments defined by the sets of hierarchically ordered IVs that are most significantly related to response categories of the DV (i.e., high QoL). The CHAID technique is nonparametric with no assumptions of normal distribution which needed to be met, and is robust to outliers. The method allows for data analysis with missing values as a valid category ('floating predictor') (Kass, 1980). Considering that the CHAID accommodates analysis with missing information, the original dataset (without imputed values) was preserved for this study. Additionally, CHAID method performs optimally with large samples of at least 1,000 cases (Antipov \& Pokryshevskaya, 2010) because of its use of multiple splits. The large size of the dataset used in this study therefore allows us to appropriately apply the CHAID method. A detailed description of how CHAID operates can be found in "IBM SPSS Decision Trees 21" (IBM, 2012), Kass (1980), and Ritschard (2013).

We ran the Exhaustive CHAID tree growing option algorithm, which allows the same IV (if appropriate and relevant) to be included in more than one group profile (tree branch) (IBM, 2012). The tree structure was customized to include a minimum number of 20 records per cell (the default is 100) in the parent nodes and 10 cases (the default is 50) in the child nodes that offer larger discriminatory power by 
capturing more variation in the data. By the same rationale, rather than using the default option (i.e., three-level tree), the tree depth was set at five levels allowing for more detailed results in terms of a possibly larger number of terminal nodes. The significance level for splitting and merging nodes was set using the default option to $\alpha$ merge, split, with adjusted (controlled for $\alpha$ inflation) $p$-value $\leq 0.05$ using the Bonferroni correction method for multiple simultaneous testing. The quality (generalizability and stability) of the CHAID model was assessed by using a fivefold crossvalidation method and misclassification risk information in the CHAID output table. In addition, we tested the predictive accuracy of the CHAID model using receiver operating characteristic (ROC) analysis that offers a measure of an area under the curve (AUC) which represents the probability that the model will correctly predict a noteworthy outcome of interest (i.e., QoL level) (Fawcett, 2006). The closer the AUC is to 1.00, the better the predictive ability of the model (Fawcett, 2006). All analyses were performed with SPSS for Windows v.24.0.

\section{Additional Analysis}

In order to determine which WHOQOL-BREF scale items best represent its respective domain associated with QoL levels, we ran a separate CHAID analysis with 24 items (see Appendix A for the list of WHOQOL-BREF items) as IVs and with QoL global item as the DV using the same tree growing criteria described above. General Health item was excluded from this analysis since it is not a part of any domain of the scale. The rationale for item-level analysis was based on its utility as noted by Von Steinbüchel et al. (2006) who showed that the associations between the 24 items and QoL measured by the WHOQOL-BREF differ between specific subgroups of older adults. Since the results based on four dimensions may not generalize across sub-groups, the authors propose using item-level profiles, which may have a greater potential to detect the possible sources of variability in reported QoL (Von Steinbüchel et al., 2006). By employing CHAID analysis, our study is able to demonstrate in addition to which WHOQOL-BREF items representing their respective dimension are the most salient in affecting various QoL levels, which configurations of interacting items across four dimensions operating in unison significantly influence QoL levels. Hence, we believe that this study can offer a more nuanced knowledge about possible other sources of variability within and between delineated subgroups in reported QoL in the main analysis.

\section{Results}

\section{Sample Characteristics}

In the total sample $(n=1,910), 54 \%$ of respondents were men. The average age of participants was 71.9 years $(S D=6.9$; age range 62 to 99$)$ and about one in four survey participants $(n=504 ; 26.4 \%)$ lived alone. Of the sample $43.1 \%(n=813)$ respondents reported having completed secondary education and $41.5 \%(n=783)$ 
reported some tertiary education. Nearly $50 \%$ of respondents were urban dwellers, $25.7 \%$ and $24.5 \%$ of respondents represented semirural, and rural settings respectively.

Of the 1,910 participants, 17 did not answer the question on overallQoL(WHOQOLBREF item). Therefore, both the descriptive statistics by level of QoL and the CHAID analysis with QoL as DV were performed with sample of 1,893 participants. Table 1 displays sample characteristics on 20 IVs (all entered into CHAID analysis) by QoL low-, medium-, and high scores. Chi-square associations were statistically significant for 15 variables at $p<0.01$ or better.

According to descriptive results, within total sample, the majority of respondents (84.4\%) reported high QoL $\left(4^{\text {th }}\right.$ and $5^{\text {th }}$ quintile groups of high and highest scores on satisfaction with QoL, $233(12.3 \%)$ reported medium QoL ( ${ }^{\text {rd }}$ quintile), and low QoL ( $1^{\text {st }}$ and $2^{\text {nd }}$ quintile) was reported by $62(3.3 \%)$ individuals. The prevalence of high QoL among all respondents decreased with increasing age after 75 years. Respondents with high education (tertiary) predominantly represented the high QoL group at the significantly different rate in comparison to those found in medium and low QoL groups. Conversely, significantly more participants with low education (primary or less) were found in the low QoL group than those reporting medium and high QoL. With regard to geographic area of residence, significant differences between three QoL categories were detected only for rural dwellers who were more prevalent in medium and high QoL groups compared to those reporting low QoL. Those living alone were more frequently found in the group reporting low QoL compared to the medium and high QoL groups. With regard to neighborhood quality, in contrast to respondents representing medium and high QoL groups, a significantly higher proportion of those in low QoL group perceived the social aspect of their neighborhood as unsatisfactory. There were significant differences related to all WHOQOL-BREF subscales between groups reporting low-, medium-, and high QoL Low QoL reporters had significantly lower scores on all dimensions compared to those in medium- and high QoL groups.

\section{CHAID Analysis}

The graphic output, a map of the entire tree structure based on CHAID analysis is shown in Fig. 1.

The tree resulted in 15 terminal nodes classifying respondents into 15 distinctive sub-groups with specific profiles variously defined by sets of interactive factors most strongly related to a specific category of the QoL. The algorithm stopped the tree growth at the four-level depth despite the stopping rule for allowing the tree to grow up to five-levels in depth. This means that the algorithm did not detect more variables significantly related to any QoL level. The risk estimate of $0.122(S E=0.008)$ indicated that the model classified overall $87.8 \%$ of the cases correctly into each QoL category (i.e. low, medium and high) with an AUC of $0.885,95 \%$ CI [0.828, $0.942]$; this implies a relatively high classification accuracy rate. The five-fold crossvalidation resulted in misclassification risk at $0.138(S E=0.008)$, which indicates 
Table 1 Sample Characteristics on 20 Variables by Low-, Medium-, and High QoL Score $(n=1893)$

\begin{tabular}{|c|c|c|c|c|}
\hline \multirow[t]{2}{*}{ Variables } & \multicolumn{3}{|l|}{ QoL } & \multirow[t]{2}{*}{$\mathrm{X}^{2}(d f, n)$} \\
\hline & Low $n(\%)$ & Medium $n(\%)$ & High $n(\%)$ & \\
\hline Total sample & $62(3.3)$ & $233(12.3)$ & $1598(84.4)$ & \\
\hline Gender & & & & $2.250(2,1876)$ \\
\hline Men & $28(45.2)$ & $116(50.0)$ & $842(53.2)$ & \\
\hline Women & $34(54.8)$ & $116(50.0)$ & $740(46.8)$ & \\
\hline Age & & & & $24.117(8,1868)^{* *}$ \\
\hline $62-67$ & $14(23.3)$ & $64(27.8)$ & 499 (31.6) & \\
\hline $68-74$ & $16(26.7)$ & $90(39.1)$ & $626(39.7)$ & \\
\hline $75-79$ & $13(21.7)$ & $35(15.2)$ & $232(14.7)$ & \\
\hline $80-84$ & $7(11.7)$ & $18(7.8)$ & $135(8.6)$ & \\
\hline $85+$ & $10(16.7)$ & $23(10.0)$ & $86(5.4)$ & \\
\hline Education & & & & $44.540(4,1872) * * *$ \\
\hline Primary or less & $19(30.6)$ & $51(22.1)$ & 219 (13.9) & \\
\hline Secondary & $25(40.3)$ & $122(52.8)$ & $660(41.8)$ & \\
\hline Tertiary & $18(29.0)$ & $58(25.1)$ & $700(44.3)$ & \\
\hline \multicolumn{5}{|l|}{ Living area } \\
\hline Rural & $7(11.3)$ & $68(29.2)$ & $389(24.3)$ & $8.631(2,1893)^{* *}$ \\
\hline Semirural & $23(37.1)$ & $62(26.6)$ & $400(25.0)$ & $4.696(2,1893)$ \\
\hline Urban & $33(53.2)$ & $103(44.2)$ & 797 (49.9) & $3.012(2,1893)$ \\
\hline \multicolumn{5}{|l|}{ Living arrangement } \\
\hline Live alone & $32(51.6)$ & $89(38.2)$ & 377 (23.6) & $43.548(2,1893)^{* * *}$ \\
\hline Spouse/partner & $24(38.7)$ & $139(59.7)$ & $1179(73.8)$ & $51.830(2,1893)^{* * *}$ \\
\hline Multigenerational family & $3(4.8)$ & $15(6.4)$ & $91(5.7)$ & $0.307(2,1893)$ \\
\hline Friends & 0 & $1(0.4)$ & $5(0.3)$ & $0.291(2,1893)$ \\
\hline Residential care & $5(8.1)$ & $2(0.9)$ & $8(0.5)$ & $43.452(2,1893)^{* * * *}$ \\
\hline Can rely on neighbors & & & & $103.188(4,1870)^{* * * *}$ \\
\hline (strongly) disagree & $22(36.7)$ & $47(20.7)$ & $123(7.8)$ & \\
\hline neutral & $18(30.0)$ & $81(35.7)$ & $426(26.9)$ & \\
\hline (strongly) agree & $20(33.3)$ & 99 (43.6) & $1034(65.3)$ & \\
\hline Belong to the place & & & & $153.602(4,1878)^{* * * *}$ \\
\hline (strongly) disagree & $16(26.2)$ & $25(10.9)$ & $37(2.3)$ & \\
\hline neutral & $14(23.0)$ & $79(34.3)$ & 297 (18.7) & \\
\hline (strongly) agree & $31(50.8)$ & $126(54.8)$ & $1253(79.0)$ & \\
\hline Difficult to get in contact & & & & $50.623(4,1869)^{* * * *}$ \\
\hline (strongly) disagree & $30(49.2)$ & $106(46.1)$ & $1029(65.2)$ & \\
\hline neutral & $17(27.9)$ & $81(35.2)$ & $417(26.4)$ & \\
\hline (strongly) agree & $14(23.0)$ & $43(18.7)$ & $132(8.4)$ & \\
\hline Loneliness & & & & $343.872(4,1850)^{* * * *}$ \\
\hline never & $3(4.8)$ & $26(11.6)$ & $662(42.3)$ & \\
\hline sometimes & $30(48.4)$ & $153(68.3)$ & $862(55.1)$ & \\
\hline often & $29(46.8)$ & $45(20.1)$ & $40(2.6)$ & \\
\hline
\end{tabular}


Table 1 (continued)

\begin{tabular}{|c|c|c|c|c|}
\hline \multirow[t]{2}{*}{ Variables } & \multicolumn{3}{|l|}{ QoL } & \multirow[t]{2}{*}{$\mathrm{X}^{2}(d f, n)$} \\
\hline & Low $n(\%)$ & Medium $n(\%)$ & High $n(\%)$ & \\
\hline \multicolumn{5}{|c|}{ WHOQOL-BREF domains } \\
\hline Health overall & & & & $636.117(4,1888)^{* * *}$ \\
\hline (very) dissatisfied & $50(80.6)$ & $95(41.1)$ & $91(5.7)$ & \\
\hline Fair & $6(9.7)$ & $85(36.8)$ & $223(14.0)$ & \\
\hline (very) satisfied & $6(9.7)$ & $51(22.1)$ & $1281(80.3)$ & \\
\hline Physical & & & & $476.960(8,1888)^{* * *}$ \\
\hline Lowest & $56(90.3)$ & $150(64.4)$ & $227(14.2)$ & \\
\hline Low & $4(6.5)$ & $38(16.3)$ & $279(17.5)$ & \\
\hline Medium & 0 & $22(9.4)$ & $228(14.3)$ & \\
\hline High & $2(3.2)$ & $17(7.3)$ & $515(32.3)$ & \\
\hline Very high & 0 & $6(2.6)$ & $344(21.6)$ & \\
\hline Psychological & & & & $587.051(8,1888) * * *$ \\
\hline Lowest & $55(88.7)$ & $158(68.1)$ & $188(11.8)$ & \\
\hline Low & $4(6.5)$ & $47(20.3)$ & $343(21.5)$ & \\
\hline Medium & $2(3.2)$ & $24(10.3)$ & $540(33.9)$ & \\
\hline High & $1(1.6)$ & $1(0.4)$ & $188(11.8)$ & \\
\hline Very high & 0 & $2(0.9)$ & $335(21.0)$ & \\
\hline Social & & & & $180.593(6,1878) * * *$ \\
\hline Lowest & $42(70.0)$ & $146(63.2)$ & $423(26.7)$ & \\
\hline Low-medium & $12(20.0)$ & $50(21.6)$ & $393(24.8)$ & \\
\hline Medium-high & $4(6.7)$ & $26(11.3)$ & $432(27.2)$ & \\
\hline High & $2(3.3)$ & $9(3.9)$ & $339(21.4)$ & \\
\hline Environmental & & & & $425.058(8,1886)^{* * *}$ \\
\hline Lowest & $50(80.6)$ & $136(58.4)$ & $208(13.1)$ & \\
\hline Low & $8(12.9)$ & $61(26.2)$ & $410(25.8)$ & \\
\hline Medium & $4(6.5)$ & $19(8.2)$ & $294(18.5)$ & \\
\hline High & 0 & $17(7.3)$ & $415(26.1)$ & \\
\hline Very high & 0 & 0 & $264(16.6)$ & \\
\hline
\end{tabular}

$n$ varies due to missing data

${ }^{* *} p<.005 ; * * * p<.0005$

that the obtained tree model is not over-fitted, and in addition would not significantly vary among several random sub-samples of the same population.

With regard to the relevance of IVs entered for analysis, the CHAID selected seven out of 20 variables which significantly contributed to the final model. As shown in Fig. 1, the most significant factor related to QoL was degree of satisfaction with mental health functioning (PSY domain scores) which subdivided/split the total sample into four main groups (tree branches). The subsequent splits of these groups were made by the six IVs: general health, physical health (PHYS domain), living alone, loneliness, neighborhood qualities (i.e. perceived availability of help), and ENVIR domain. Notably, the last three were reoccurring variables across groups 
indicating their particular importance in influencing QoL. In various constellations the seven variables determined both between- and within-groups variability.

While each segment was distinct (significantly different from one another), the majority of them shared a common characteristic with regard of reporting in particular the lowest and/or low satisfaction with psychological functioning (PSY domain scores) (see Fig. 1: nodes 1 and 2 with subsequent splits). That is, within the total sample, respondents with low QoL scores (combined nodes 1 and 2: $n=59 ; 95 \%$ ), medium QoL scores (combined nodes 1 and 2: $n=206 ; 88 \%$ ), and high QoL scores (combined nodes 1 and $2: n=535 ; 33 \%$ ) with relatively poor mental health were represented in 12 out of the 15 segments. To add more detail, almost an entire subsample of participants with low QoL (55 out of 62) followed by those reporting medium QoL (158 out of 233) fell within the segment characterized by the lowest score on the PSY domain (node 1). The majority of participants $(1,063$ out of 1,598$)$ with high QoL fell within segments with low-medium and above medium scores on the PSY domain (node 3 and 4).

Thus, depending on the nature and constellations of the additional factors interacting with on the average low PSY domain scores, the percentage of high QoL respondents was relatively low (least representative of the total high QoL group) in comparison to those with low- and medium QoL scores. For example, low scores on PSY domain in the context of some personal and contextual resources resulted in high QoL for some (e.g., having relatively good overall health and being satisfied with social support; Fig. 1: nodes 1-7-17). In general, a careful examination of the 12 segments reveals that it is the unique combinations of lowest and low mental health functioning categories along with particular categories of other personal and contextual factors that place a person at different likelihood of reporting a given satisfaction level with QoL,

Table 2 lists the values of all profiling variables included in the CHAID model (Fig. 1) significantly contributing to low, medium, and high to QoL across seven segments with predominantly the highest prevalence within-group QoL score.

Below we report on the seven subgroups with the highest prevalence of low-, medium-, and high QoL. However, the reference to the highest prevalence of a given QoL level demands clarification on its selection criteria which, in the interest of space, we provide information on in Appendix B.

\section{Group Profiles With the Highest Prevalence of Low QoL}

The set of variables associated with the highest prevalence of low QoL were: very poor mental and general health, loneliness, and a lack of social/instrumental support in one's neighborhood (Table 2: segment 1 and 2).

For one subgroup of low QoL reporters, relatively frequent experiences of loneliness contributed to the highest rate of low QoL at 53.2\% (segment 2, terminal node 13). In a separate subgroup with similar experiences of poor (mental) health and loneliness (albeit occasional), lack of instrumental support in one's neighborhood was a particularly influential factor leading to low QoL reported by $45 \%$ individuals (segment 1 , terminal node 22 ). 
Table 2 Group Profiles Based on Variables Predominantly Associated With the Highest Rate of Low (-), Medium (0), and High (+) QoL Level

\begin{tabular}{|c|c|c|c|c|c|c|c|}
\hline \multirow[t]{2}{*}{ Variable } & \multicolumn{7}{|c|}{ Segments and nodes } \\
\hline & $\begin{array}{l}1 \\
1-5-12-22\end{array}$ & $\begin{array}{l}2 \\
1-5-13\end{array}$ & $\begin{array}{l}3 \\
1-6-14\end{array}$ & $\begin{array}{l}4 \\
2-8-18\end{array}$ & $\begin{array}{l}5 \\
2-9-20-25\end{array}$ & $\begin{array}{l}6 \\
3-11\end{array}$ & $\begin{array}{l}7 \\
4\end{array}$ \\
\hline \multicolumn{8}{|l|}{$Q o L-P S Y$} \\
\hline Lowest & -0 & - & 0 & & & & \\
\hline Lowest, low & & & & 0 & + & & \\
\hline Low, medium & & & & & & + & \\
\hline$>$ Medium & & & & & & & + \\
\hline \multicolumn{8}{|l|}{ Health overall } \\
\hline (very) poor & -0 & - & & & & & \\
\hline (very) poor, fair & & & 0 & & & & \\
\hline fair & & & & 0 & & & \\
\hline$>$ fair & & & & & + & & \\
\hline \multicolumn{8}{|l|}{ QoL-PHYS } \\
\hline \multicolumn{8}{|l|}{ Lowest } \\
\hline$>$ Lowest & & & & & & + & \\
\hline \multicolumn{8}{|l|}{ Loneliness } \\
\hline Sometimes & -0 & & & & + & & \\
\hline$>$ Sometimes & & - & & & & & \\
\hline \multicolumn{8}{|l|}{ Live alone } \\
\hline Yes & & & $\mathbf{0}$ & & & & \\
\hline \multicolumn{8}{|l|}{ No } \\
\hline $\begin{array}{l}\text { Can rely on help } \\
\text { (strongly) disagree } \\
>\text { (strongly) disagree }\end{array}$ & -0 & & & & & & \\
\hline \multicolumn{8}{|l|}{ Neutral } \\
\hline \multicolumn{8}{|l|}{$>$ Neutral } \\
\hline \multicolumn{8}{|l|}{ QoL-ENVIR } \\
\hline Lowest & & & & $\mathbf{0}$ & & & \\
\hline$>$ Low & & & & & + & & \\
\hline$\%$ QoL low a & 45.0 & 53.2 & 8.1 & 1.9 & 0.0 & 0.2 & 0.2 \\
\hline$\%$ QoL medium & 55.0 & 42.6 & 62.2 & 42.6 & 0.0 & 1.6 & 0.6 \\
\hline$\%$ QoL high & 0.0 & 4.3 & 29.7 & 55.6 & 100.0 & 98.2 & 99.2 \\
\hline
\end{tabular}

Variables listed in approximal order according to the CHAID model

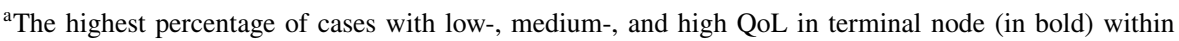
segments

According to the item-level results (available upon request), the highest prevalence of low QoL was most strongly related to the low(est) score on the item "meaningfulness in life" representing the PSY domain in interaction either with low ability to perform "activities of daily living" (henceforth ADL) or dissatisfaction with "work capacity", with both items representing the PHYS health domain. 
$\mathbf{a}$

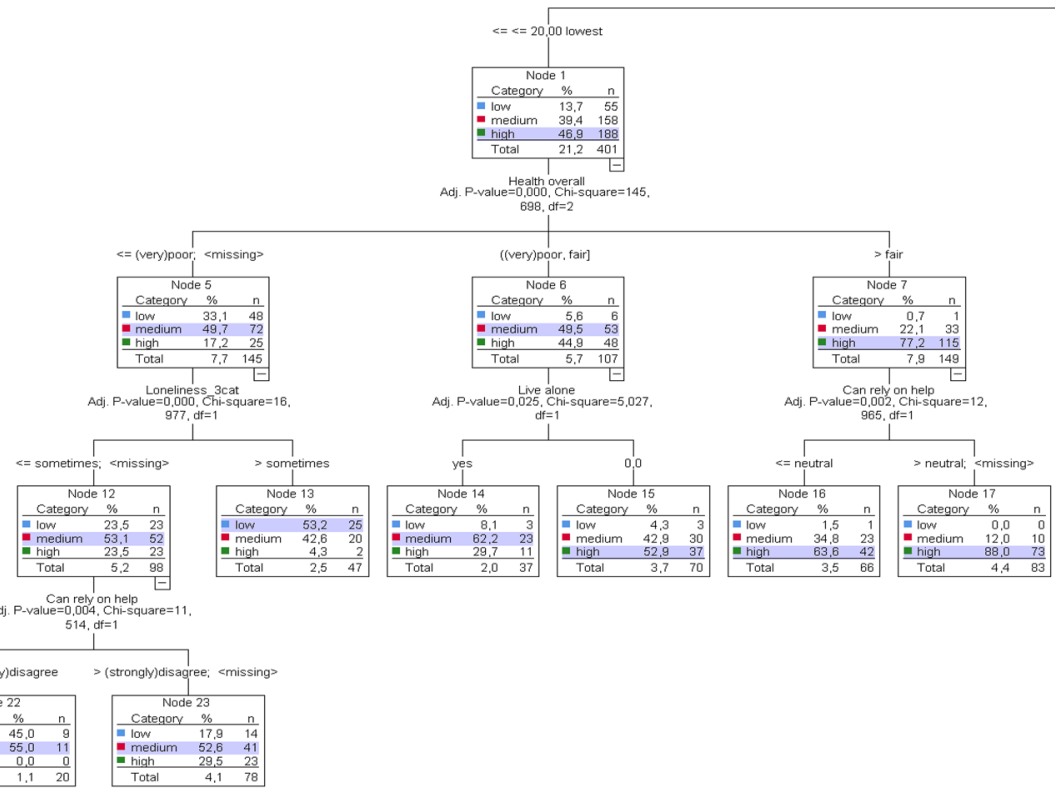

b
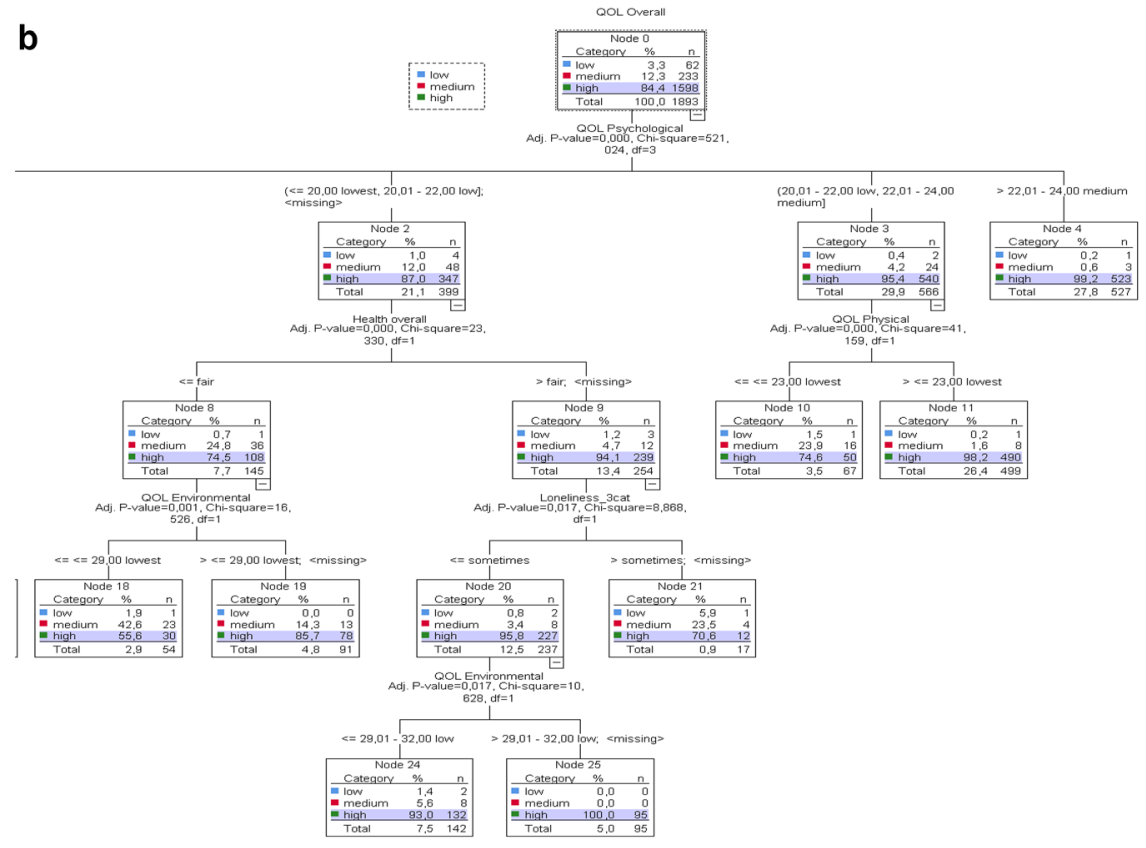

Fig. 1 Tree Diagram Showing Variables Significantly Influencing QoL Levels 


\section{Group profiles with the highest prevalence of medium QoL}

The set of variables associated with the highest prevalence of medium QoL were: relatively poor mental health, (very) poor to fair general health, occasional loneliness, lack of social support in one's neighborhood, living alone, and ENVIR domain (lowest satisfaction score) (Table 2: segments 1, 3, and 4).

With regard to subgroup profiles, the highest prevalence at $62.2 \%$ (segment 3 , terminal node 14) of medium QoL resulted from very poor mental health in interaction with general health status along a continuum from very poor to moderately satisfactory (or fair), and living alone. The next highest rate of medium QoL at 55\% was related to an identical constellation of factors from the main CHAID model evident in the low QoL groups described above (segment 1, terminal node 22). In contrast to the two subgroups, individuals comprising segment 4 were characterized by slightly better psychological functioning and better overall health (i.e., moderately satisfactory) in combination with the lowest satisfaction with the environmental aspects of QoL. This constellation of factors defined $42.6 \%$ of medium QoL reporters (segment 4, terminal node 18).

According to the item-level results, the highest prevalence of medium QoL was most strongly associated with perceiving life as meaningful (PSY domain) to some degree at least. The meaningfulness in life item significantly interacted with some (or no) satisfaction with work capacity as opposed to greater satisfaction (PHYS domain), some or no "life enjoyment" (PSY domain), low "self-esteem" (PSY domain), and having very few or no opportunities in "pursuing leisure activities" (ENVIR domain).

\section{Group Profiles With the Highest Prevalence of High QoL}

The set of variables associated with the highest rates of high QoL were: mental health status ranging among respondents from relatively poor to excellent, fair or better general health, lowest and above satisfaction with physical health, occasional loneliness, and ENVIR domain (low and above satisfaction scores) (Table 2: segments 5-7).

In one subgroup, $100 \%$ in prevalence of high QoL was connected to relatively poor mental health in interaction with moderately satisfactory or better general health, occasional loneliness, and low or higher satisfaction with the environmental aspects of life (segment 5, terminal node 25). The profile that defined a distinct sub-group was related to moderately good or better (e.g., excellent) mental health which was the only factor resulting in reports of high QoL at the second highest rate at $99.2 \%$ (segment 7, terminal node 4). The third highest prevalence of high QoL (98.2\%) was found in a subgroup characterized by moderate to low satisfactory mental health in interaction with very low or higher satisfaction with physical functioning (segment 6, terminal node 11).

According to the item-level results, the highest prevalence of high QoL was most prominently associated with reports of a highly meaningful life (PSY domain) in the context of good to very good physical health, as indicated by "having enough 
energy", and work capacity (items representing PHYS domain). In addition, reported "access to health services" or "having sufficient income" (items representing ENVIR domain) were important factors which enhanced high QoL for some respondents.

\section{Discussion}

In line with previous Norwegian (Hansen \& Daatland, 2016) and international investigations (Hawthorne et al., 2013; Netuveli et al., 2008; Von Steinbüchel et al., 2006), the descriptive results showed that high QoL remained rather common in the second half of life. In this study, QoL slightly decreased with increasing age after 75 years and this trend paralleled that reported elsewhere (Hansen \& Daatland, 2016; Hawthorne et al., 2006, 2013; Motel-Klingebiel et al., 2004). With regard to geographical area, compared to urban and semi-rural dwellings, a significantly higherQoL was found among rural residents. The only other study using the WHOQOLBREF scale reported similar results for a Brazilian sample (Tavares et al., 2014). With a few exceptions (e.g., gender, education, semirural and urban dwelling, and living with a multigenerational family), most of the personal and contextual factors from descriptive results differed significantly across groups defined variously by low, medium, and high QoL. On the other hand, in the CHAID model only seven of twenty variables when in interaction and specific constellations exerted a significant impact on QoL. This discrepancy between descriptive and CHAID results, particularly with regard to socio-demographic variables excluded from the model (i.e., age, gender, education) is intriguing and will be discussed below.

According to the tree model, the level of psychological functioning in interaction with either subjectively evaluated overall health status or physical functioning was the most powerful factor related to QoL outcomes. This result corresponded to findings from several other studies using the WHOQOL-BREF measurement (Hanestad et al., 2004; Kalfoss et al., 2008; Motel-Klingebiel et al., 2004; Suárez et al., 2018; Weber et al., 2015) and indicates that psychological functioning assumes the role of health status as asserted by Motel-Klingebiel et al. (2004). Along the same lines, it is likely that the perception and appraisal of QoL may be dominated by a person's mental state operating as a 'mediator' between health and QoL. According to the CHAID model, in addition to mental functioning and health status, individual life circumstances related to psychosocial and environmental factors must be included in understanding a person's experience of QoL. Similarly, based on a path model, Landau and Litwin (2001) concluded that the connection between life satisfaction and psychosocial variables in late old age is mediated both by functional health (i.e., physical capacity) and psychosocial resources (e.g., social network supportiveness). Based on the CHAID model in our study, we were able to reveal not only the type of jointly operating factors but also how they varied (e.g., in formations) across and within groups defined by low, medium, and high QoL.

Results from the additional WHOQOL-BREF item level analysis are also interesting to note. The item 'meaning in life' seemed not only to be the most salient facet representing the PSY domain, but also the crucial element associated with 
QoL. This finding is congruent with those presented by Pinquart (2002), Schnell (2009), and Zika and Chamberlain (1992) who demonstrated that the issue regarding meaningfulness (or meaninglessness) of life is an important factor in shaping mental health and perceptions of well-being. Paskulin and Molzahn (2007), noted that after health satisfaction, the 'meaning in life' item significantly contributed most to the overall QoL measured by the WHOQOL-BREF scale. The meaning in life as a construct has been overlooked in QoL studies with general populations of older people. Here we show that the construct is worthy to include in future community research.

\section{Profiles of Low QoL Groups}

According to the CHAID analysis, two sub-groups had the highest prevalence of low QoL at 53.2\% and 45\% respectively. Although they both shared a common characteristic related to very poor mental health and (very) poor general health, the magnitude of experienced loneliness seemed to be an important factor in differentiating profiles of these groups. That is, in one subgroup, the likelihood of reporting low QoL increased alongside more frequently experienced (e.g. sometimes to often) feelings of loneliness. However, in another subgroup, although 'less severe' loneliness seemed to reduce the percentage of low QoL, a deficit in instrumental support in one's immediate neighborhood was coincident with an increase of low QoL. Thus, in interaction with poor mental and overall health that appeared to rob a person's life of quality, the lack of satisfying or desired social contacts, possibly eliciting the feeling of being abandoned or forgotten, seemed to strip life of quality still further. In general, our model illuminates previous findings showing that QoL among the severely ill older adults in particular, is very sensitive to and affected by psychosocial factors (Bowling et al., 2003; Kalfoss \& Halvorsrud, 2009; Puts et al., 2007; Wilhemson et al., 2005).The CHAID profiling confirmed the importance of neighbors and especially those who can provide practical support or companionship as being particularly important to perceptions of quality of life for those older persons who are ill and live alone (Bowling et al., 2003; Hellström et al., 2004; Kalfoss \& Halvorsrud, 2009).

The WHOQOL-BREF item-level analysis has further revealed that challenging life circumstances have led persons in low QoL groups to view their life as utterly meaningless especially when functional impairments (e.g., mobility or fatigue), highly likely restricted activities of daily living (ADL) (e.g., self-care, household chores), which could no longer be executed or accomplished as desired. Since the ability to independently perform ADL has been reported by older adults as a highly valued and the most important determinant of living a qualitatively good life (Kalfoss \& Halvorsrud, 2009; Netuveli \& Blane, 2008; Skevington \& O'Connell, 2004), the loss of functional health may elicit strong emotional reactions, and for some, produce severe psychological deterioration (e.g., feelings of hopelessness and depression) (Caltabiano et al., 2008). Stillman et al. (2009), noted that the lack of social interactions, perhaps in the wake of health loss, may be associated with loneliness, the erosion of self-worth, and a global reduction in the perception of life as meaningful. Our study adds support to this claim. 
Interestingly, for individuals in both low QoL groups, information on their living arrangement (household structure) was not included in the CHAID model. Based on a Norwegian report (Hansen \& Daatland, 2016) this finding is counterintuitive because it could be expected that living alone would be one in a set of factors (e.g., in addition to feeling lonely) defining low QoL profiles. There are at least two plausible explanations for this non-significant outcome. First, living alone was excluded from the CHAID model because its effect on the QoL was too weak. Second, the experience of living alone seem to outweight it as a mere fact of doing so, as shown by Ytter (2010).

\section{Profiles of Medium QoL Groups}

The majority of individuals reporting medium QoL had relatively poor mental health but on the average their overall health was better that in the low QoL groups. In contrast to those with low QoL, these persons seemed to have positive self-regard, perceived their life as enjoyable to some degree and filled with at least some meaning. This relatively positive mental state interacted with at least some satisfaction of being physically able to perform work (e.g., being independent).

Living alone was the particular life situation of individuals in the sub-group with the highest rate of medium QoL at $62.2 \%$. Although all had very poor mental health, as did those reporting low QoL, as a group they differed significantly from the latter by also including persons with somewhat 'better' self-rated health, which in turn seemed to fuel one's life with some meaning as indicated by the item-level analysis. It may also be that being able to retain at least some level of independence in performing ADL may be gratifying and may somewhat counteract the fact of living alone. Considering that our finding corroborated that reported by Ytter (2010) and by Dale et al. (2012), such an interpretation is quite plausible. Notably, the lack of loneliness as a variable in the profile of that group may further support such an explanation. Nonetheless, we do not imply that researchers and caring services should divert their attention from older people living alone, even if they report moderate QoL. The understanding that an assessment of moderate QoL is a relatively good situation to be in would be ill-founded, as evidenced by our results.

One distinctive profile defining the medium QoL groups seemed to be identical to that of individuals in the two low QoL groups; that was that they were characterized by very poor (mental) health, loneliness, and lacking a 'helping hand' in their immediate neighborhood. However, the findings from the supplementary analysis revealed that these like profiles might actually not be the case. In contrast to the low QoL group, those reporting medium QoL were relatively satisfied with their abilities to perform ADL. This indicates that despite compromised health, the nature of their illness was very probably less physically incapacitating than those in the low QoL group, though we cannot rule out the influence of adaptive coping strategies or other resources. For example, the literature on coping with chronic illnesses indicates that the longer people who have had an illness or disability the better they seemed to cope with it (Caltabiano et al., 2008). The critical question is whether coping strategies will remain adaptive or become maladaptive in the long-term, and this seems to be an important issue to be addressed in further QoL research and in the formulation of social care (e.g., in preventive) interventions. 
In comparison to persons in the two medium QoL groups just described, individuals constituting yet another medium QoL group had better mental and overall health, however they were highly dissatisfied with restricted leisure opportunities and activities (ENVIR domain) as indicated by the item-level analysis. Although this finding is supported by studies which have demonstrated that often times reduction in leisure activities seemed to follow deteriorations in health (Silverstein \& Parker, 2002), we cannot be certain that this might be occurring here. In addition, limited (if any) participation in individually judged meaningful recreational pursuits might have taken away the possibility to enjoy life and this in turn might have affected appraisal of life quality as being less optimal. According to Kalfoss (2010), Norwegian older adults place leisure activities and hobbies high on the ranking of importance to their QoL.

\section{Profiles of High QoL Groups}

Within the overall high QoL group, positive mental health was the sole contributor to high QoL for about 30\% of respondents. However, at about the same rate, those with less optimal or even poor psychological functioning also appraised their life as highly satisfactory. The additional CHAID of item-level results indicated that in one high QoL sub-group, moderate or higher satisfaction with mental health seemed to be related to viewing one's life as highly meaningful and enjoyable, and as noted, this constituted the single factor having the main effect on high QoL. However, not all those reporting high QoL were alike.

One high QoL subgroup consisted of persons reporting medium and slightly lower satisfaction with mental health along with rating satisfaction with physical health to be the lowest or a little better. This indicates that for this particular subgroup, functional health was particularly important to their QoL whether or not perceived as optimal. The item-level analysis suggested that this sub-group may be represented by individuals who viewed their life as meaningful although not necessarily as highly meaningful (i.e., to some degree) and enjoyed life to at least some degree. These items interacted with having at least some energy and work capacity, possibly allowing them to stay independent. In addition, it may be that persons in this group might possess adaptive skills in coping with reduced functional capacity, possibly related to one's sense of mastery, control over, and adjustment to their medical condition (Caltabiano et al., 2008). In that case, the profile of this group could possibly support the well-being paradox phenomenon. For instance, within personality theories concerning ageing and the sense of identity, the older adult is viewed as maintaining both positive self-esteem and enhanced abilities to cope with negative life events. Among others, coping abilities to manage problems and accommodation of goals or reduction of aspiration in the face of actual and impeding adversities are theorized mechanisms of maintaining well-being in later life (Baltes \& Baltes, 1990; Brandtstaedter \& Greve, 1994).

For a distinct subset of participants, the CHAID model identified a constellation of four interacting factors contributing to high QoL at the highest rate of $100 \%$. These included overall poor mental functioning in unison with good general health (i.e., fair or better), occasional or absent feelings of loneliness, and low or somewhat higher satisfaction with 
environmental aspects of QoL. The CHAID item-level analysis further suggested that viewing life as a little or at the most to some degree meaningful, but enjoying it anyway, combined with a secure financial situation, and satisfaction with health care services are likely characteristics specific to the profile of this segment. This subset of individuals deserves particular attention for at least two reasons. First, its profile was not shared with any person reporting either medium or low QoL. This indicates that the features identified by the model are unique only for individuals with high QoL. Second, as implied by item-level analysis, financial security and/or satisfaction with access and quality of care services evidently does matter for some older people, because of their contribution to increased prevalence of high QoL to one hundred percent. According to the Norwegian report (Hansen \& Daatland, 2016), satisfaction with health care services had no impact on QoL in older adults but having adequate money did. Although financial assets cannot be dismissed, Motel-Klingebiel et al. (2004) showed that the impact of money on QoL at later stages in life is low. The fact that in our sample financial security was important for six percent of all individuals with high QoL may support this conclusion.

\section{Nonsignificant CHAID Results: Sociodemographics}

In this study, the tie between QoL and socio-demographics such as age, gender, and education within the context of other personal and environmental factors was either absent or too weak to reach statistical significance, hence these variables did not enter the CHAID model. Although it is possible that this result could be due to methodological factors at work, our model of QoL was clearly socio-demographically neutral, supporting the WHOQOL Group definition of QoL (WHO, 1998), which does not state or imply the influence of socially stratified groups on QoL outcomes. According to one cross-national study investigating social inequalities in QoL assessed by the WHOQOL-BREF, the differences in QoL of older adults were linked to life course effects rather than age per se or 'societal embeddedness' (Motel-Klingebiel et al., 2004). Our investigation seems to corroborate this finding.

\section{Limitations}

The findings of this study should be evaluated in the light of three possible limitations. The first attaches to the nature of the CHAID model itself. Although the overall classification accuracy of the model for the entire sample was satisfactory, with the relative low risk of misclassifying a case into an incorrect category, about $50 \%$ of respondents with low QoL shared some of the profiles with medium QoL groups. In terms of the practical significance of this in applied settings (e.g., in care intervention planning), this information may be misleading and could result in overlooking those with a qualitatively poor life if they are confused with those reporting their life as satisfactory. Thus, incorporating additional factors which could better distinguish (purify) the profiles of low QoL from medium QoL groups would highly likely increase specificity of the model. However, we need to underscore the exploratory nature of the present study, hence the results should not be devalued. Another potential concern is that the respondents in our 
study may not have been fully representative of the target population in terms of gender distribution. In our study, men were over-represented relative to women. However, since gender appear to be a rather weak source of variability in reports of QoL, as evidenced by Norwegian studies (e.g., Hansen \& Daatland, 2016), we remain confident that the impact of this shortcoming on the results will be minimal. Lastly, for reasons arising from the preservation of anonymity, it was not possible to check statistically on whether the characteristics of non-respondents (e.g., demographics, health status) differed from those of study participants. Therefore, we cannot rule out the effect of systematic differences between respondents and non-respondents (i.e., respondent bias) on the results. Thus, although these methodological drawbacks may limit the generalizability of our findings to other populations, we believe that the random sample selection, rarely used in other QoL studies with older populations (Hawthorne et al., 2006), will have mitigated the potency of these limitations.

\section{Strength}

This investigation demonstrated the impact of simultaneously operating multiple factors on QoL through an exhaustive CHAID approach that has not been previously used either in any previous QoL research or more specifically in investigations of QoL in older populations. We think that this method is useful in exploring and identifying the sources of heterogeneity in QoL assessments in large datasets. The variability between and within groups would be likely concealed had we used another methodological approach unless some a priori determined interactions between chosen factors were entered into multivariate analysis, as has been done, for example by Cummins et al. (2007) or Motel-Klingebiel et al. (2004).

Thus far, the research investigating QoL in older populations as measured by the WHOQOL-BREF reported the impact of health, mental functioning, social and environmental conditions on QoL in terms of their aggregate mean scores. Although these studies yield useful information, our approach offered further insight into group profiles, hence more specific information on identified sources of between and within more or less subtle group differences. Von Steinbuichel et al. (2006) suggested that in addition to the information based on the four WHOQOL-BREF domain scores, pinpointing the effects of the scale items may incur a "surplus in research on QoL in old age" (p. 122). Our study benefited from this recommendation, and therefore we believe that there is a need for more research with other samples in order to confirm or disconfirm the usefulness of the item-level approach in QoL research with older adults (e.g., in substantive QoL theory building through longitudinal study designs).

\section{Conclusion}

As shown both in this and previous QoL studies, the fact that personal (e.g., biology/ health, mental state), social (e.g. social interaction or lack of it), and environmental (e.g., neighborhood characteristics, leisure) play an important role in QoL is beyond dispute. We have also demonstrated that there are significant variations at all QoL levels 
with regard to the personal and contextual factors which have been explored, but these differentials seem to be socio-demographically neutral. This leads us to conclude that from a QoL perspective, the nature and sources of personal concerns may therefore provide better insights into what influences the overall quality of older people's lives. If such factors are not explored and well understood, QoL they may remain an idiosyncratic mystery and so be avoided or left unattended in social or health care settings (Pennacchini et al., 2011). Our findings caution against erroneously equating older age with disease which could only reinforce negative attitudes towards aging (ageism), and erroneously assuming quality of life equals the absence of psychological distress or ill health, hence ignoring older persons in need for support and assistance.

Obviously, personal and environmental conditions are not static and may change for anyone, regardless of socio-demographic status. Paraphrasing Bandura (1982), the factors that influence peoples' lives may often be chance encounters, which are not predictable in advance. This said, longitudinal or participatory research and periodical assessments of QoL are important in detecting areas in need for intervention whether the locus of intervention is within the person, the family or the community. For example, engaging older persons in research on identifying and understanding what and how community aspects support or do not support their QoL may be a very important means to provide policy makers with information to form the basis for resource allocation. According to Raphael (2010), this type of research from a policy perspective is rare.

Funding Open access funding provided by NTNU Norwegian University of Science and Technology (incl St. Olavs Hospital - Trondheim University Hospital). This study did not receive any funding.

\section{Declarations}

Consent to Participate Returned and completed questionnaires were taken to demonstrate consent to participate in the study. The datasets generated and analyzed for the current study are not publicly available for data protection reasons.

Ethical Treatment of Experimental Subjects (Animal and Human) All procedures performed in studies involving human participants were in accordance with the ethical standards of the institutional and national research committee the Norwegian Regional Committee of Medical Research Ethics [permission number 2015/214] and with the 1964 Helsinki declaration and its later amendments or comparable ethical standards.

Conflict of Interest The authors have no relevant financial or non-financial interest to disclose.

Open Access This article is licensed under a Creative Commons Attribution 4.0 International License, which permits use, sharing, adaptation, distribution and reproduction in any medium or format, as long as you give appropriate credit to the original author(s) and the source, provide a link to the Creative Commons licence, and indicate if changes were made. The images or other third party material in this article are included in the article's Creative Commons licence, unless indicated otherwise in a credit line to the material. If material is not included in the article's Creative Commons licence and your intended use is not permitted by statutory regulation or exceeds the permitted use, you will need to obtain permission directly from the copyright holder. To view a copy of this licence, visit http://creativecommons.org/ licenses/by/4.0/. 


\section{Appendix A}

\section{WHOQOL-BREF Scale: Domains and 26 Items}

\begin{tabular}{ll}
\hline Scale domains and items & \\
\hline Domain 1: Physical health $(P H Y S)$ & Domain 3: Social relationships (SOC) \\
\hline Pain and discomfort & Personal relationships \\
Energy and fatigue & Sexual activity/intimacy \\
Sleep and rest & Practical social support \\
Dependence on medication & \\
Mobility & Domain 4: Environment (ENVIR) \\
Activities of daily living & Financial resources \\
Working capacity & Acquisition of new information and skills \\
& Recreation and leisure (opportunities, participation) \\
Domain 2: Psychological (PSY) & Home environment \\
Positive feelings & Health and social care (accessibility, quality) \\
Negative feelings & Physical safety and security \\
Self-esteem & Physical environnement (pollution, noise, trafic) \\
Thinking, learning, memory, concentration & Transport \\
Body image & \\
Meaningfulness of life & Global items \\
& Overall quality of life \\
& General health \\
\hline
\end{tabular}

After Motel-Klingebiel et al. (2004) and Skevington et al. (2004)

\section{Appendix B}

\section{Selection Process of the Highest Rate of Within-Group Cases on the QoL Level}

On the tree branch with several nodes the percentage of cases may increase with each subsequent node (or added variable) for some subgroup and decrease following the split for another subgroup. If the rate of cases in the terminal node increases in relation to the rate of cases in the preceding node on a given variable category, this rate was reported. In contrast, if the rate of cases in the terminal node decreases in relation to the rate of cases in the previous node, reporting was then omitted. 


\section{The excerpt of the CHAID model}

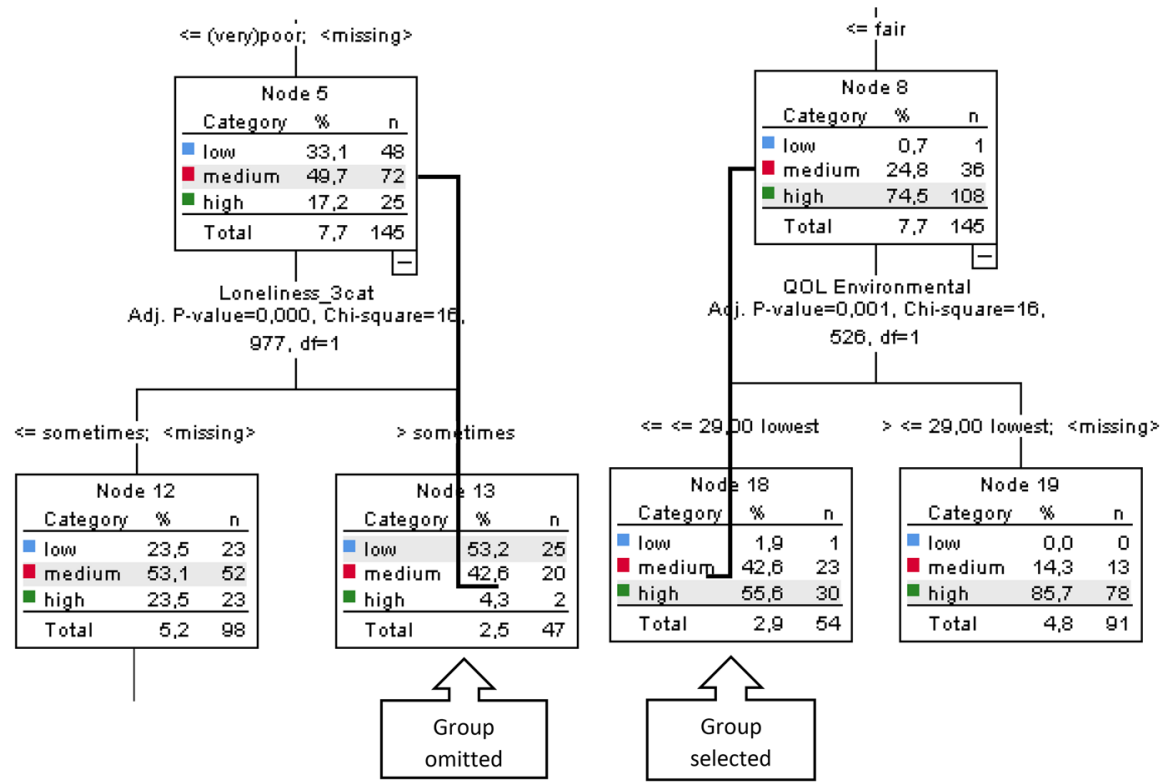

\section{References}

Antipov, E., \& Pokryshevskaya, E. (2010). Applying CHAID for logistic regression diagnostics and classification accuracy improvement. Journal of Targeting, Measurement and Analysis for Marketing, 18(2), 109-117. https://doi.org/10.1057/jt.2010.3

Baltes, P. B., \& Baltes, M. M. (1990). Psychological perspectives on successful aging: The model optimization with compensation. In P. B. Baltes \& M. M. Baltes (Eds.), Successful aging: Perspectives from behavioral sciences (pp. 1-34). Cambridge University Press.

Bandura, A. (1982). The psychology of chance encounters and life paths. American Psychologist, 37(7), $747-755$.

Bascu, J., Jeffery, B., Abonyi, S., Johnson, S., Novik, N., Martz, D., \& Oosman, S. (2014). Healthy aging in place: Perceptions of rural older adults. Educational Gerontology, 40(5), 327-337. https://doi. org/10.1080/03601277.2013.802191

Barstad, A. (1995). Levekår i by og land [Living conditions in the city and countryside] (Samfunnsspeilet 1/95). https://www.ssb.no/sosiale-forhold-og-kriminalitet/artikler-og-publikasjoner/_attachment/ 69734?_ts=137dab7e1a8

Bäckman, L., \& MacDonald, S. W. S. (2006). Death and cognition: Synthesis and outlook. European Psychologist, 11(3), 224-235. https://doi.org/10.1027/1016-9040.11.3.224

Blazer, D. G. (2003). Depression in late life: Review and commentary. The Journals of Gerontology. Series A, Biological Sciences and Medical Sciences, 58(3), 249-265. https://doi.org/10.1093/ gerona/58.3.M249

Blekesaune, A., \& Haugen, M. S. (2018). Aging in Norwegian rural and urban communities. European Countryside, 10(2), 232-246. https://doi.org/10.2478/euco-2018-0014

Bowling, A., \& Gabriel., Z., Dykes, J., Dowding, L. M., Evans, O., Fleissig, A., Banister, D., \& Sutton, S. . (2003). Let's ask them: A national survey of definitions of quality of life and its enhancement among people aged 65 and over. International Journal of Aging and Human Development, 56(4), 269-306. https://doi.org/10.2190/BF8G-5J8L-YTRF-6404 
Boyle, P. A., Barnes, L. L., Buchman, A. S., \& Bennett, D. A. (2009). Purpose in Life is associated with mortality among community-dwelling older adults. Psychosomatic Medicine, 71(5), 574-579. https://doi.org/10.1097/2FPSY.0b013e3181a5a7c0

Brandmaier, A. M., Ram, N., Wagner, G. G., \& Gerstorf, D. (2017). Terminal decline in well-being: The role of multi-indicator constellations of physical health and psychosocial correlates. Developmental Psychology, 53(5), 996-1012. https://doi.org/10.1037/dev0000274

Brandtstädter, J., \& Greve, W. (1994). The aging self: Stabilizing and protective processes. Developmental Review, 14(1), 52-80. https://doi.org/10.1006/drev.1994.1003

Burholt, V., \& Dobbs, C. (2012). Research on rural ageing: Where have we got to and where are we going in Europe? Journal of Rural Studies, 28(4), 432-446. https://doi.org/10.1016/j.jrurstud.2012.01.009

Caltabiano, M. L., Safarino, E., \& Byrne, D. (2008). Health psychology: Biopsychosocial interactions (2nd Australasian ed.). John Wiley and Sons Australia.

Carrasco, L. R., Laidlaw, K., \& Power, M. J. (2011). Suitability of the WHOQOL-BREF and WHOQOLOLD for Spanish older adults. Aging and Mental Health, 15(5), 595-604. https://doi.org/10.1080/ 13607863.2010.548054

Carta, M. G., Aguglia, E., Caraci, F., Dell'Osso, L., Di Sciascio, G., Drago, F., Del Giudice, E., Faravelli, C., Hardoy, M. C., Lecca, M. E., Moro, M. F., Calò, S., Casacchia, M., Angermeyer, M. C., \& Balestrieri, M. (2012). Quality of life and urban / rural living: Preliminary results of a community survey in Italy. Clinical Practice and Epidemiology in Mental Health, 8(1), 169-174. https://doi.org/10.2174/ 2F1745017901208010169

Chachamovich, E., Trentini, C., \& Fleck, M. P. (2007). Assessment of the psychometric performance of the WHOQOL-BREF instrument in a sample of Brazilian older adults. International Psychogeriatric, 19, 635-646. https://doi.org/10.1017/S1041610206003619

Crnek-Georgeson, C. K. T., Wilson, L. A., \& Page, A. (2017). Factors influencing suicide in older rural males: A review of Australian studies. Rural and Remote Health, 17(4), 4020. https://doi.org/10. 22605/RRH4020

Cummins, R. A., Walter, J. W., \& Woerner, J. (2007). Well-being of Australians: Groups with the highest and the lowest well-being in Australia (Report No. 16.1). Deakin University and Australian Unity Limited. http://www.acqol.com.au/uploads/surveys/survey-016-1-report.pdf

Dale, B., Söderhamn, U., \& Söderhamn, O. (2012). Self-care ability among home-dwelling older people in rural areas in southern Norway. Scandinavian Journal of Caring Sciences, 26(1), 113-122. https://doi.org/10.1111/j.1471-6712.2011.00917.x

Fawcett, T. (2006). An introduction to ROC analysis. Pattern Recognition Letters, 27(8), 861-874. https:// doi.org/10.1016/j.patrec.2005.10.010

Fischer, J. A.V. (2009). Happiness and age cycles - Return to start...?: On the functional relationship between subjective well-being and age (OECD Social, Employment and Migration Working Papers No. 99). OECD Publishing. https://doi.org/10.1787/220573570724

Fortney, J. C., Harman, J. S., Xu, S., \& Dong, F. (2010). The association between rural residence and the use, type, and quality of depression care. The Journal of Rural Health, 26, 205-213. https://doi.org/ 10.1111/j.1748-0361.2010.00290.x

Gabriel, Z., \& Bowling, A. (2004). Quality of life from the perspectives of older people. Aging and Society, 24, 675-691. https://doi.org/10.1017/S0144686X03001582

Gerstorf, D., Ram, N., Mayraz, G., Hidajat, M., Lindenberger, U., Wagner, G. G., \& Schupp, J. (2010). Late-life decline in well-being across adulthood in Germany, the United Kingdom, and the United States: Something is seriously wrong at the end of life. Psychology and Aging, 25(2), 477-485. https://doi.org/10.1037/2Fa0017543

Hanestad, B. R., Rustøen, T., Knudsen, Ø., Lerdal, A., \& Wahl, A. K. (2004). Psychometric properties of the WHOQOL-BREF questionnaire for the Norwegian general population. Journal of Nursing Measurement, 12(2), 147-159. https://doi.org/10.1891/jnum.2004.12.2.147

Hansen, T., \& Daatland, S. O. (2016). Aldring, mestringsbetingelser og livskvalitet [Aging, mastery preconditions, and quality of life] (Rapport IS-2475). Helsedirektoratet. https://www.helsedirektoratet.no/rapporter/aldringmestringsbetingelser-og-livskvalitet/Aldring,\%20mestringsbetingelser\%20og\%20livskvalitet.pdf/_/ attachment/inline/8eb8c451-2e98-4e41-859c-9008c05a8ded:fddecbd64bb4227305494f4314cea8aa97e894ac/ Aldring,\%20mestringsbetingelser\%20og\%20livskvalitet.pdf

Hansen, T., \& Slagsvold, B. (2012). The age and subjective well-being paradox revisited: A multidimensional perspective. Norsk Epidemiologi, 22(2), 187-195. https://doi.org/10.5324/NJE.V22I2.1565 
Hawthorne, G., Herrman, H., \& Murphy, B. (2006). Interpreting the WHOQOL-BREF: Preliminary population norms and effect sizes. Social Indicators Research, 77(1), 37-59. https://doi.org/10.1007/ s11205-005-5552-1

Hawthorne, G., Korn, S., \& Richardson, J. (2013). Population norms for the AQoL derived from the 2007 Australian National Survey of Mental Health and Wellbeing. Australian and New Zealand Journal of Public Health, 37(1), 7-16. https://doi.org/10.1111/1753-6405.12004

Hellström, Y., Persson, G., \& Hallberg, I. R. (2004). Quality of life and symptoms among older people living at home alone. Journal of Advanced Nursing, 48(6), 584-593. https://doi.org/10.1111/j.13652648.2004.03247.x

Helvik, A.-S., Engdal, K., Krokstad, S., \& Selbæk, G. (2011). A comparison of life satisfaction in elderly medical inpatients and the elderly in a population-based study: Nord-Trøndelag Health Study 3. Scandinavian Journal of Public Health, 39(4), 337-344. https://doi.org/10.1177/1403494811405093

Hermalin, A. I., Ofsted, M. B., \& Metha, K. (2002). The vulnerable and their potential disadvantages. In A. I. Hermalin (Ed.), The well-being of the elderly in Asia: A four-country comparative studies (pp. 461518). The University of Michigan Press. https://www.psc.isr.umich.edu/pubs/books/ElderlyInAsia fullText.pdf

Hwang, H. L., Liang, W. M., Chiu, Y. N., \& Lin, M. R. (2003). Suitability of the WHOQOL-BREF for community-dwelling older people in Taiwan. Age and Aging, 32(6), 593-600. https://doi.org/10. 1093/ageing/afg102

IBM (2012). IBM SPSS Decision Trees 21. IBM Corporation. http://www.sussex.ac.uk/its/pdfs/SPSS_ Decision_Trees_21.pdf

Inder, K. J., Lewin, T. J., \& Kelly, B. J. (2012). Factors impacting on the well-being of older residents in rural communities. Perspectives in Public Health, 132(4), 182-191. https://doi.org/10.1177/2F1757913912447018

Kalfoss, M. (2010). Quality of life among Norwegian older adults: Focus group results. Research in Gerontological Nursing, 3(2), 100-112. https://doi.org/10.3928/19404921-20091207-99

Kalfoss, M., \& Halvorsrud, L. (2009). Important issues to quality of life among Norwegian older adults: An exploratory study. The Open Nursing Journal, 3, 45-55. https://doi.org/10.2174/1874434600903010045

Kalfoss, M. H., Low, G., \& Halvorsrud, L. (2017). Identity process among older Norwegians living in urban and rural areas. Western Journal of Nursing Research, 40(5), 701-724. https://doi.org/10. 1177/2F0193945916687514

Kalfoss, M. H., Low, G., \& Molzahan, A. E. (2008). The suitability of the WHOQOL-BREF for Canadian and Norwegian older adults. European Journal of Aging, 5(1), 77-89. https://doi.org/10.1007/ s10433-008-0070-z

Kass, G. V. (1980). An exploratory technique for investigating large quantities of categorical data. Applied Statistics, 29(2), 119-127. https://doi.org/10.2307/2986296

Kirchengast, S., \& Haslinger, B. (2008). Gender differences in health-related quality of life among healthy aged and old-aged Austrians: Cross-sectional analysis. Gender Medicine, 5(3), 270-278. https://doi.org/10.1016/j.genm.2008.07.001

Lacy, H. P., Smith, D. M., \& Ubel, P. A. (2006). Hope I die before I get old: Mispredicting happiness across the adult lifespan. Journal of Happiness Studies, 7, 167-182.

Landau, R., \& Litwin, H. (2001). Subjective well-being among the old-old: The role of health, personality and social support. International Journal of Aging and Human Development, 52(4), 265-280. https://doi.org/10.2190/2FRUMT-YCDX-X5HP-P2VH

Llwellyn, A. M., \& Skevington, S. M. (2016). Evaluating a new methodology for providing individualized feedback in healthcare on quality of life and its importance, using the WHOQOL-BREF in a community population. Quality of Life Research, 25(3), 605-614. https://doi.org/10.1007/ s11136-015-1132-2

Lubetkin, E. I., Jia, H., Franks, P., \& Gold, M. R. (2005). Relationship among sociodemographic factors, clinical conditions, and health-related quality of life: Examining the EQ-5D in the U.S. general population. Quality of Life Research, 14(10), 2187-2196. https://doi.org/10.1007/s11136-005-8028-5

Mascaro, N., \& Rosen, D. H. (2005). Existential meaning's role in the enhancement of hope and prevention of depressive symptoms. Journal of Personality, 73(4), 985-1014. https://doi.org/10.1111/j. 1467-6494.2005.00336.x

Mastekaasa, A., \& Moum, T. (1984). The perceived quality of life in Norway: Regional variations and contextual effects. Social Indicators Research, 14(4), 385-419. https://doi.org/10.1007/BF00300450

McDonald, M. J., Wong, P. T. P., \& Gingras, D. T. (2012). Meaning-in-life and development of a brief version of the Personal Meaning Profile. In P. T. P. Wong (Ed.), Personality and clinical psychology 
series. The human quest for meaning: Theories, research, and applications (2nd ed., pp. 357-382). Routledge/Taylor \& Francis Group.

McKnight, P. E., \& Kashdan, T. B. (2009). Purpose in life as a system that creates and sustains health and well-being: An integrative, testable theory. Review of General Psychology, 13(3), 242-251. https:// doi.org/10.1037/2Fa0017152

Milbourne, P. (2012). Growing old in rural places. Journal of Rural Studies, 28(4), 315-317. https://doi. org/10.1016/j.jrurstud.2012.10.001

Morgan, J., Robinson, O., \& Thompson, T. (2015). Happiness and age in European Adults: The moderating role of gross domestic product per capita. Psychology of Aging, 30(3), 544-551.

Mosqueda, L., \& Dong, X. (2011). Elder abuse and self-neglect: "I don't care anything about going to the doctor, to be honest...." JAMA, 306(5), 532-540. https://doi.org/10.1001/jama.2011.1085

Motel-Klingebiel, A., Von Kondratowitz, H. J., \& Tesch-Römer, C. T. (2004). Social inequality in the later life: Cross-national comparison of quality of life. European Journal of Aging, 1(1), 6-14.https://doi.org/10.1007/2Fs10433-004-0001-6

Mroczek, D. K., \& Kolarz, C. M. (1998). The effect of age on positive and negative affect: A developmental perspective on happiness. Journal of Personality and Social Psychology, 75, 1333-1349.

Nes, R. B. (2019). Fakta om livskvalitet og trivsel i Norge [Facts about quality of life and well-being in Norway]. https://www.fhi.no/fp/psykiskhelse/livskvalitet-og-trivsel/livskvalitet-og-trivsel/

Nes, R. B., Nilsen, T. S., Hauge, L. J., Eliertsen, M., Gustavson, K., Aarø, L. E., \& Røysamb, E. (2020). Fra nord til sør: Livskvalitet i Norge 2019 [From north to south: Live quality in Norway 2019] (Rapport 2020). Folkehelseinstituttet. [Norwegian Institute of Public Health; NIPH]. https://www.fhi.no/ contentassets/21c14cb7d5924b779a0d6e26c4064af4/livskvalitet-i-norge-2019-rapport.pdf

Netuveli, G., \& Blane, D. (2008). Quality of life in older ages. British Medical Bulletin, 85(1), 113-126. https://doi.org/10.1093/bmb/ldn003.

Netuveli, G., Wiggins, R. D., Hildon, Z., Montgomery, S. M., \& Blane, D. (2006). Quality of life at older ages: Evidence from the English longitudinal study of aging (wave 1). Journal of Epidemiology and Community Health, 60(4), 357-363. https://doi.org/10.1136/2Fjech.2005.040071

Paskulin, G. L. M., \& Molzahn, A. (2007). Quality of life of older adults in Canada and Brazil. Western Journal of Nursing Research, 29(1), 10-26. https://doi.org/10.1177/0193945906292550

Pennacchini, M., Bertolaso, M., Elvira, M. M., \& De Marinis, M. G. (2011). A brief history of the quality of life: Its use in medicine and in philosophy. La Clinica Terapeutica, 162(3), e99-e103. https:// www.researchgate.net/profile/Marta-Bertolaso/publication/51455603_A_brief_history_of_the_ Quality_of_Life_its_use_in_medicine_and_in_philosophy/links/5c9e0bcb299bf111694f3571/Abrief-history-of-the-Quality-of-Life-its-use-in-medicine-and-in-philosophy.pdf

Pinquart, M. (2002). Creating and maintaining purpose in life in old age: A meta-analysis. Aging International, 27(2), 90-114. https://doi.org/10.1007/s12126-002-1004-2

Puts, M. T. E., Shekary, N., Widdershoven, G., Heldens, J., Lips, P., \& Deeg, D. J. H. (2007). What does quality of life mean to older frail and non-frail community-dwelling adults in the Netherlands? Quality of Life Research, 16(2), 263-277. https://doi.org/10.1007/s11136-006-9121-0

Raphael, D. (2010). Health promotion and quality of life in Canada: Essential readings. Canadian Scholars' Press.

Reker, G. T., Peacock, E. J., \& Wong, P. T. P. (1987). Meaning and purpose in life and well-being: A life-span perspective. Journal of Gerontology, 42(1), 44-49. https://doi.org/10.1093/geronj/42.1.44

Ritschard, G. (2013). CHAID and Earlier Supervised Tree Methods. In J.J. McArdle \& G. Ritschard (Eds.), Contemporary Issues in Exploratory Data Mining in Behavioral Sciences (pp. 48-74). Routeledge. http://mephisto.unige.ch/pub/publications/gr/Ritschard-chaid-edm.pdf

Ryff, C. D. \& Keyes, C. L. M. (1995). The structure of psychological well-being revisited. Journal of Personality and Social Psychology, 69(4), 719-727. https://doi.org/10.1037/0022-3514.69.4.719

Schnell, T. (2009). The sources of meaning and Meaning in Life Questionnaire (SoMe): Relations to demographics and well-being. The Journal of Positive Psychology, 4(6), 483-499. https://doi.org/ $10.1080 / 17439760903271074$

Scocco, P., \& Nassuato, M. (2017). The role of social relationships among elderly community-dwelling and nursing home residents: Findings from a quality of life study. Psychogeriatrics, 17(4), 231-237. https://doi.org/10.1111/psyg.12219

Silverstein. M., \& Parker, M. G. (2002). Leisure activities and quality of life among the oldest old in Sweden. Research on Aging, 24(5), 528-547. https://doi.org/10.1177/2F0164027502245003 
Sivertsen, H., Bjørkløf, G. H., Engedal, K., Selbæk, G., \& Helvik, A. S. (2015). Depression and quality of life in older persons: A review. Dementia and Geriatric Cognitive Disorders, 40(5-6), 311-339. https://doi.org/10.1159/000437299

Skevington, S., Lotfy, M., \& O'Connell, K. (2004). The World Health Organization's WHOQOL-BREF quality of life assessment: Psychometric properties and results of the international field trial. A Report from the WHOQOL Group. Quality of Life Research, 13, 299-310. https://doi.org/10. 1023/B:QURE.0000018486.91360.00

Skevington, S. M., \& O’Connell, K. A. (2004). Can we identify the poorest quality of life? Assessing the importance of quality of life using the WHOQOL-100. Quality of Life Research, 13(1), 23-34. https://doi.org/10.1023/B:QURE.0000015317.71791.be

Skinner, W., Andrews, G. J., \& Cutchin, M. P. (2014). Geographies of ageing: Progress and possibilities after two decades of change. Progress in Human Geography, 39(6), 776-799. https://doi.org/10. 1177/2F0309132514558444

Statistics Norway. (2015). Statistikkbanken [StatBank Norway]. Population and population changes 1986-2019. https://www.ssb.no/en/statbank/table/07459/

Statistics Norway. (2016). Social relations, survey on living, 2015. https://www.ssb.no/en/sosiale-forholdog-kriminalitet/statistikker/soskon/hvert-3-aar/2016-06-24

Statistics Norway. (2020). Livskvalitet i Norge 2020 [Life quality in Norway 2020] (Rapport 2020/35). Statistisk Sentralbyrå [Statistics Norway]. https://www.ssb.no/sosiale-forhold-og-kriminalitet/artiklerog-publikasjoner/_attachment/433414?_ts=17554096418

Stillman, T. F., Baumeister, R. F., Lambert, N. M., Crescioni, A. W., DeWall, C. N., \& Finchman, F. D. (2009). Alone and without purpose: Life loses meaning following social exclusion. Journal of Experimental Social Psychology, 45(4), 686-694. https://doi.org/10.1016/2Fj.jesp.2009.03.007

Suárez, L., Tay, B., \& Abdullah, F. (2018). Psychometric properties of the World Health Organization WHOQOL-BREF Quality of Life assessment in Singapore. Quality of Life Research, 27, 29452952. https://doi.org/10.1007/s11136-018-1947-8

Sund, E. R., Jørgensen, S. H., Jones, A., Krogstad, S., \& Heggdal, M. (2007). The influence of social capital on self-rated health and depression -The Nord-Trøndelag health study (HUNT). Norsk Epidemiologi, 17(1), 59-69. https://doi.org/10.5324/nje.v17i1.173

Swift., H.J., Vauclair, C. M., Abrams, D., Bratt, C., Marques, S., \& Lima, M. L. (2014). Revisiting the paradox of well-being: The importance of national context. Journal of Gerontology. Series B: Psychological Sciences and Social Sciences, 69(6), 920-929.

Tavares, D. M. S., Bolina, A. F., Dias, F. A., Ferreira, P. C. S., \& Haas, V. J. (2014). Quality of life of elderly. Comparison between urban and rural areas. Investigacion Educacion Enfermeria, 32(3), 401-413. https://doi.org/10.17533/udea.iee.v32n3a05

United Nations. (1982). Provisional guidelines on standard international age classifications (Statistical Papers Series M No.74). United Nations. https://unstats.un.org/unsd/publication/SeriesM/SeriesM_ 74e.pdf

United Nations. (2003). United Nations demographic yearbook review: National reporting of age and sex-specific data, implications for international recommendations. United Nations. https://unstats. un.org/unsd/demographic-social/products/dyb/documents/techreport/ageandsex.pdf

Vogel, N., Schilling, O. K., Wahl, H.-W., Beekman, A. T. F., \& Penninx, B. W. J. H. (2013). Time-todeath-related change in positive and negative affect among older adults approaching the end of life. Psychology and Aging, 28(1), 128-141. https://doi.org/10.1037/a0030471

Von dem Knesebeck, O., Wahrendorf, M., Hyde, M., \& Siegrist, J. (2007). Socioeconomic position and quality of life among older people in 10 European countries: Results from the SHARE study. Aging and Society, 27(2), 269-284. https://doi.org/10.1017/S0144686X06005484

Von Steinbüchel, N., Lischetzke, T., Gurny, M. \& Eid, M. (2006). Assessing quality of life in older people: Psychometric properties of the WHOQOL-BREF. European Journal of Aging, 3(2), 116-122. https://doi.org/10.1007/2Fs10433-006-0024-2

Weber, K., Canuto, A., Giannakopoulos, P., Mouchian, A., Meiler-Mititelu, C., Meiler, A., Herrmann, F. R., Delaloye, C., Lecerf, T., \& de Ribaupierre, A. (2015). Personality, psychosocial and healthrelated predictors of quality of life in old age. Aging and Mental Health, 19(2), 151-158. https://doi. org/10.1080/13607863.2014.920295

Weeks, W. B., Kazis, L. E., Shen, Y., Cong, Z., Ren, X. S., Miller, D., Lee, A., \& Perlin, J. B. (2004). Differences in health-related quality of life in rural and urban veterans. American Journal of Public Health, 94(10), 1762-1767. https://doi.org/10.2105/2Fajph.94.10.1762 
Wilhemson, K., Andresson, C., Waern, M., \& Allebeck, P. (2005). Elderly people's perspectives on quality of life. Aging and Society, 25(4), 585-600. https://doi.org/10.1017/S0144686X05003454

World Health Organization (WHO). (1998). WHOQOL User Manual. World Health Organization. http:// www.who.int/mental_health/evidence/who_qol_user_manual_98.pdf

Ytter, L. S. (2010). The experience of older men living alone. Geriatric Nursing, 31(6), 412-418. https:// doi.org/10.1016/j.gerinurse.2010.07.001

Zaninotto, P., Falaschetti, E., \& Sacker, A. (2009). Age trajectories of quality of life among older adults: Results from the English Longitudinal Study of Aging. Quality of Life Research, 18, 1301-1309. https://doi.org/10.1007/s11136-009-9543-6

Zika, S., \& Chamberlain, K. (1992). On the relation between meaning in life and psychological wellbeing. British Journal of Psychology, 83(1), 133-145. https://doi.org/10.1111/j.2044-8295.1992. tb02429.x

Publisher's Note Springer Nature remains neutral with regard to jurisdictional claims in published maps and institutional affiliations.

Lidia Santora is $\mathrm{PhD}$ candidate at joint $\mathrm{PhD}$ program Health and Behavior between Australian National University and Norwegian University of Science and Technology. Her research interest includes aging and quality of life, alcohol use in older age, ageism, and medicalization. Prior to her $\mathrm{PhD}$, she has been pursuing research in psychology of criminal behavior.

Don Byrne is a clinical psychologist and an emeritus Professor in the College of Health and Medicine at the Australian National University. He holds doctorates from the University of Adelaide (PhD) and the Norwegian University of Science and Technology (Doctor Honoris Causa), and is an elected Fellow of the Academy of the Social Sciences in Australia. Professor Byrnes research has focused on the links between psychosocial factors and the risk or incidence of physical illness across the lifespan, and particularly in relation to cardiovascular disease, and he has published extensively in this area.

Christian Klöckner is a professor in social psychology and quantitative methods at the Department of Psychology at NTNU. Currently, he leads the research group for Citizen, Environment, and Safety which studies the citizen and consumer perspective on environmental and safety questions. Christian Klöckner is the project coordinator on two EU H2020 projects. His research interests are consumer decisions in the environmental domain from everyday decisions like food choices or energy use in the household to big investment decisions such as insulating houses, photovoltaic, or electric vehicles. He is the author of more than 100 international research papers and book chapters. 